Review

\title{
Clinical importance of the superficial temporal artery in neurovascular diseases: A PRISMA-compliant systematic review
}

\author{
Kun Hou, Yunbao Guo, Kan Xu ${ }^{\bowtie}$, Jinlu $\mathrm{Yu}^{\bowtie}$ \\ Department of Neurosurgery, The First Hospital of Jilin University, Changchun, 130021, China. \\ $\triangle$ Corresponding authors: Jinlu Yu, E-mail: jlyu@jlu.edu.cn, Kan Xu, E-mail: XukanJLU@163.com, Department of Neurosurgery, The First Hospital of Jilin \\ University, 71 Xinmin Avenue, 130021, Changchun, Jilin, China. \\ (C) The author(s). This is an open access article distributed under the terms of the Creative Commons Attribution License (https://creativecommons.org/licenses/by/4.0/). \\ See http://ivyspring.com/terms for full terms and conditions.
}

Received: 2019.05.15; Accepted: 2019.08.08; Published: 2019.09.20

\begin{abstract}
The superficial temporal artery (STA) plays a very important role in neurovascular diseases and procedures. However, until now, no comprehensive review of the role of STA in neurovascular diseases from a neurosurgical perspective has ever been published. To review research on the clinical importance of STA in neurovascular diseases, a literature search was performed using the PubMed database. Articles were screened for suitability and data relevance. This paper was organized following the Preferred Reporting Items for Systematic Reviews and Meta-Analyses (PRISMA) guidelines. According to the literature, STA is one of the terminal branches of the external carotid artery and can give off scalp, muscle, and transosseous branches. STA-middle cerebral artery (MCA) bypass is very useful for intracranial ischemic diseases, including moyamoya disease, chronic ICA and MCA insufficiency, and even acute ischemic stroke. For intracranial complex aneurysms, STA bypass remains a major option that can serve as flow replacement bypass during aneurysmal trapping or insurance bypass during temporary parent artery occlusion. Occasionally, the STA can also be involved in dural AVFs (DAVFs) via to its transosseous branches. In addition, the STA can be used as an intraoperative angiography path and the path to provide endovascular treatments. Therefore, STA is a very important artery in neurovascular diseases.
\end{abstract}

Key words: Superficial temporal artery, aneurysm, arteriovenous fistula, bypass

\section{Introduction}

The superficial temporal artery (STA) is one of the terminal branches of the external carotid artery (ECA), and it together with other branches of the ECA, supplies the face and scalp [1]. Currently, the STA plays a very important role in neurovascular diseases and procedures, such as bypass for intracranial ischemic diseases, bypass for intracranial complex aneurysms, STA aneurysms, direct arteriovenous fistulas (AVFs), dural arteriovenous fistulas (DAVFs), and intraoperative angiography and endovascular treatments (EVTs) [2-7].

Therefore, a comprehensive understanding of the role of STA in neurovascular diseases is important for multiple disciplines [8]. However, until now, no comprehensive review of the clinical importance of
STA in neurovascular diseases from a neurosurgical perspective has ever been published. Hence, in this paper, a literature search was performed using the PubMed database and relevant search terms. This article was organized following the Preferred Reporting Items for Systematic Reviews and Meta-Analyses (PRISMA) guidelines and was established as a systematic review [9].

\section{Materials and methods}

This systematic review was conducted in accordance with the PRISMA guidelines [9]. Eligible English language articles (case reports, case series, and studies of the STA in neurovascular diseases) 
were identified through searches of PubMed publications (last search date was May 13 $3^{\text {th }}$ 2019).

The search algorithm used the terms "superficial temporal artery," "ischemic disease", "moyamoya disease", "aneurysm", and "arteriovenous fistula" as key words in relevant combinations. The reference lists of the identified articles were also manually searched for additional studies. The resulting flow chart is shown in Figure 1.

The inclusion criteria were as follows: a) full text was available, b) clinical data were complete, and c) STA was involved or used in all of the cases in these articles. The studies without sufficient descriptions of the STA role were excluded.

\section{Results and discussion}

After a review of the obtained literature, the current status of the role of STA in neurovascular diseases was summarized in terms of the anatomy of STA, bypass for intracranial ischemic diseases, bypass for intracranial complex aneurysms, STA aneurysm, direct AVF, DAVF, and intraoperative angiography and EVTs.

\section{(1). Applied anatomy of the STA}

The STA originates from the ECA deep to the superficial pole of the parotid and ascends approximately $1 \mathrm{~cm}$ anterior to the auditory canal [10]. It courses over the root of the zygoma, and it then divides into the frontal and parietal branches approximately 2 to $3 \mathrm{~cm}$ superior to the zygoma [11]. The STA runs with the superficial temporal vein (STV) in a wavy fashion [12].
The frontal branch of the STA supplies the skin and muscles of the forehead and anastomoses with the supraorbital and supratrochlear arteries, and the parietal branch supplies the temporal and parietal regions [13-15]. The STA forms numerous anastomoses with the middle and deep temporal artery and gives off some transosseous branches [6, $14,16]$.

The STA has a suitable length and diameter [17]. In a cadaveric study by Pinar et al. (2006), the mean diameter of the STA at the zygomatic arch was determined to be $2.7 \mathrm{~mm}$ [18]. In another study by Medved et al. (2015) based on digital subtraction angiography (DSA), the surgically average "working lengths" of the frontal and parietal branches above the upper margin of the zygoma were $106.4 \mathrm{~mm}$ and 99.7 $\mathrm{mm}$, respectively [19].

The anatomy of the STA can be evaluated via computed tomographic angiography (CTA) and DSA [20]. The anatomical angiography of the STA is shown in Figure 2.

\section{(2). Bypass for intracranial ischemic diseases}

\section{(i) Moyamoya disease}

Moyamoya disease (MMD) is characterized by progressive stenosis or occlusion of the terminal portion of the bilateral internal carotid arteries (ICAs) with extensive and abnormal moyamoya-like collaterals in the brain base [21]. In MMD, there is a risk of ischemic stroke due to hemodynamic insufficiency and intracranial hemorrhage due to fragile collaterals [22].

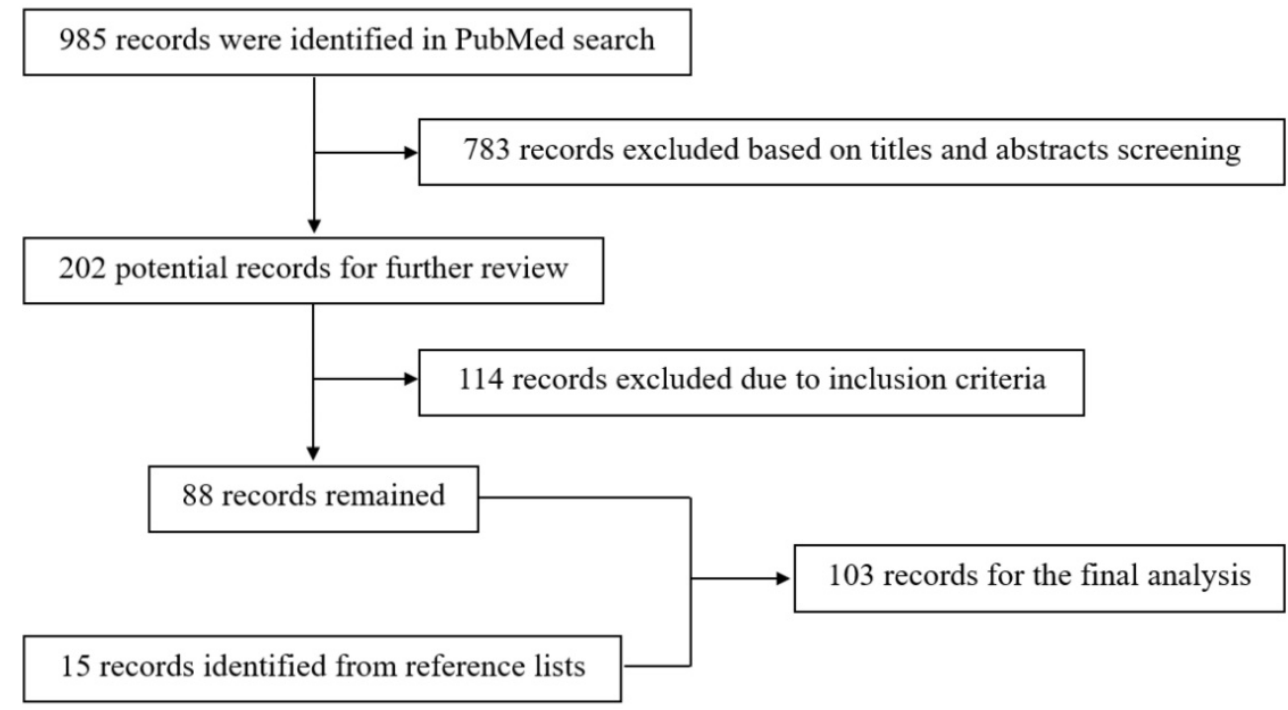

Figure 1. Flow chart of the search strategy. 


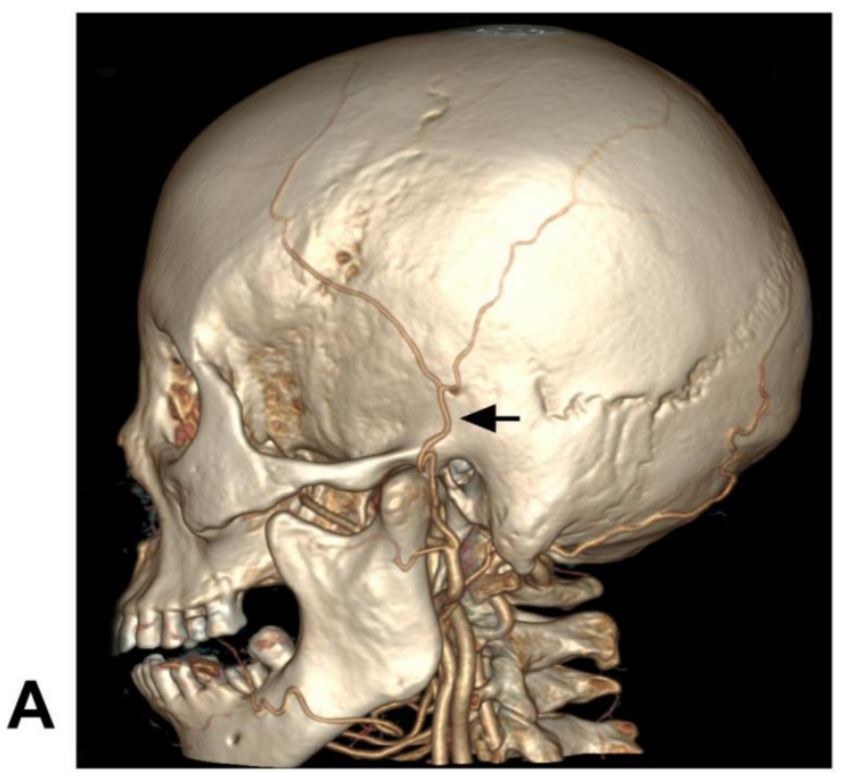

in perfusion $[28,29]$. In some patients, direct bypass can lead to spontaneous disappearance of the aneurysm in the collaterals [30]. Therefore, direct bypass plays a very important role in MMD treatment.

Direct EC-IC bypass includes STA-middle cerebral artery (MCA), STA-anterior cerebral artery (ACA), STA-posterior cerebral artery (PCA), and occipital artery (OA)-PCA anastomoses, among which STA-MCA bypass is the most common direct revascularization procedure. It is mainly used to address the MCA territory but also supports the ACA territory via leptomeningeal anastomoses [31-34].

STA-MCA bypass is typically performed using only a single STA donor branch to perform a single anastomosis. Recently, single-vessel double anastomosis and double-barrel STA-MCA bypass appeared [35-37]. These new techniques are planned to enhance STA-MCA flow capacity, but their effects as a surgical treatment for MMD remains controversial [38, 39].

Although STA-MCA bypass has been described as a low-flow system, it is sufficient for MMD [35]. Moreover, chronic dilatation of the STA has occasionally been observed after bypass surgery performed in MMD with the aim of providing more blood flow [40]. A typical case of MMD treated with STA-MCA bypass is described in Figure 3.

\section{(ii) Chronic ICA and MCA insufficiency}

Theoretically, STA-MCA bypass can be used to treat symptomatic atherosclerotic disease of the ICA and MCA [41]. Unfortunately, a trial published in the New England Journal of Medicine in 1985 and the Carotid Occlusion Surgery Study (COSS) which was published in JAMA in 2011, showed that EC-IC (mainly STA-MCA and OA-MCA to a lesser degree) bypass provided no benefit in cases of atherosclerotic narrowing or occlusion of the ipsilateral ICA or MCA $[42,43]$.

However, the trial published in the New the ECA (B) show the STA courses over the root of the zygoma before it roughy divides into the frontal and parietal branches. The STA is indicated by black and white arrows in A and B respectively. These CTA and DSA images were obtained from different patients. Abbreviations: CTA: computed tomography angiography; DSA: digital subtraction angiography; ECA: external carotid artery; STA: superficial temporal artery.

Currently, the strongest agreement regarding treatment for symptomatic MMD in the chronic phase is extracranial-intracranial (EC-IC) bypass, including direct bypass and indirect encephaloduroarteriosynangiosis [23-25].

Indirect procedures can result in excellent results in children with MMD and have therefore been widely used [26, 27]. In adult MMD, the combination of direct and indirect methods is beneficial as direct surgery can establish immediate blood flow, while indirect procedures can lead to a prolonged increase England Journal of Medicine failed to stratify patients by risk to determine which would receive the greatest benefit from this intervention [42]. Additionally, the COSS trial, which was published in JAMA, did not specifically investigate patients in whom the best medical therapy failed [43]. In addition, many researchers believe that the blood flow provided by STA-MCA bypass would be insufficient for ICA or some MCA occlusions [44-46].

Therefore, theoretically, some carefully selected patients could still benefit from STA-MCA bypass [47, 48]. Recently, it has been proposed that in some patients in whom optimal medical therapy fails or in whom flow-limiting stenosis is observed on a 
perfusion-dependent neurological examination, STA-MCA bypass could represent an effective and safe option as a rescue therapy [44, 49]. Therefore, in these patients, STA-MCA bypass is promising.

In addition, in chronic ICA and MCA insufficiency, these bypasses increase blood flow, such as the STA trunk to MCA bypass with short radial artery or STA-MCA double anastomoses, and may also be effective for providing neurological improvement in symptomatic atherosclerotic disease of the ICA and MCA [50, 51]. However, this hypothesis remains to be explored.

\section{(iii) Acute ischemic stroke}

In acute ischemic stroke (AIS) resulting from atherosclerotic occlusion of the ICA or MCA, the role of STA-MCA bypass remains poorly understood; for example, it remains unknown whether STA-MCA bypass provide any beneficial effects in affected patients [52]. Attempts at STA-MCA bypass in AIS have been continuing, even though this procedure is considered controversial [52-54].

Recently, Rice et al. (2018) performed a study of a large series and found that STA-MCA bypass, when performed in a setting of symptomatic AIS within 1 week, may confer a higher risk of perioperative stroke, including progression of ischemia or hemorrhagic transformation. Patients undergoing urgent bypass for unstable stroke symptoms might have the highest risk for perioperative stroke [52].

However, Hwang et al. (2011) found that STA-MCA bypass may be beneficial in AIS or stroke showing progress of a small infarction [55]. Lee et al. (2013) obtained a result similar to that of Hwang et al. [54]. In 2017, Park et al. proposed the following MRI-related inclusion criteria for urgent STA-MCA bypass: acute infarct volume $<70 \mathrm{ml}$ with a ratio of perfusion/diffusion lesion volume $\geq 1.2$ and a regional cerebral blood volume ratio $>0.85$ [56].

Therefore, for STA-MCA bypass performed in AIS, the mainstream belief is that acutely symptomatic patients with ICA or MCA occlusion who continue to have recurrent ischemic symptoms may, in a very few selected cases, be indicated for a bypass, although a low-flow procedure is a far better bypass than a high-flow procedure in the setting of an acute stroke when the aim is to limit hemorrhagic complications [56-58].

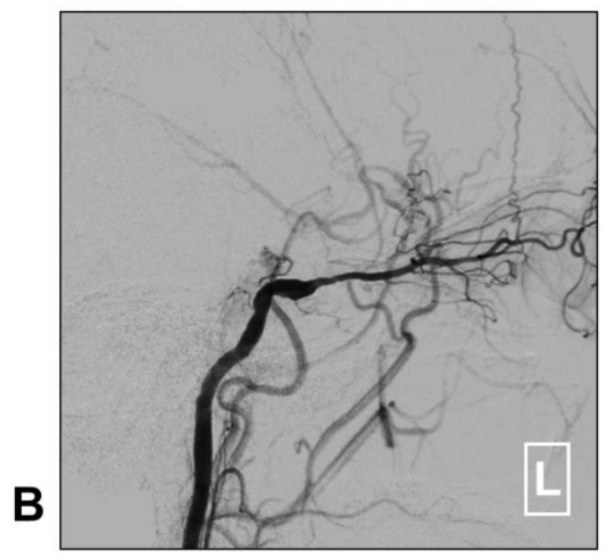

A
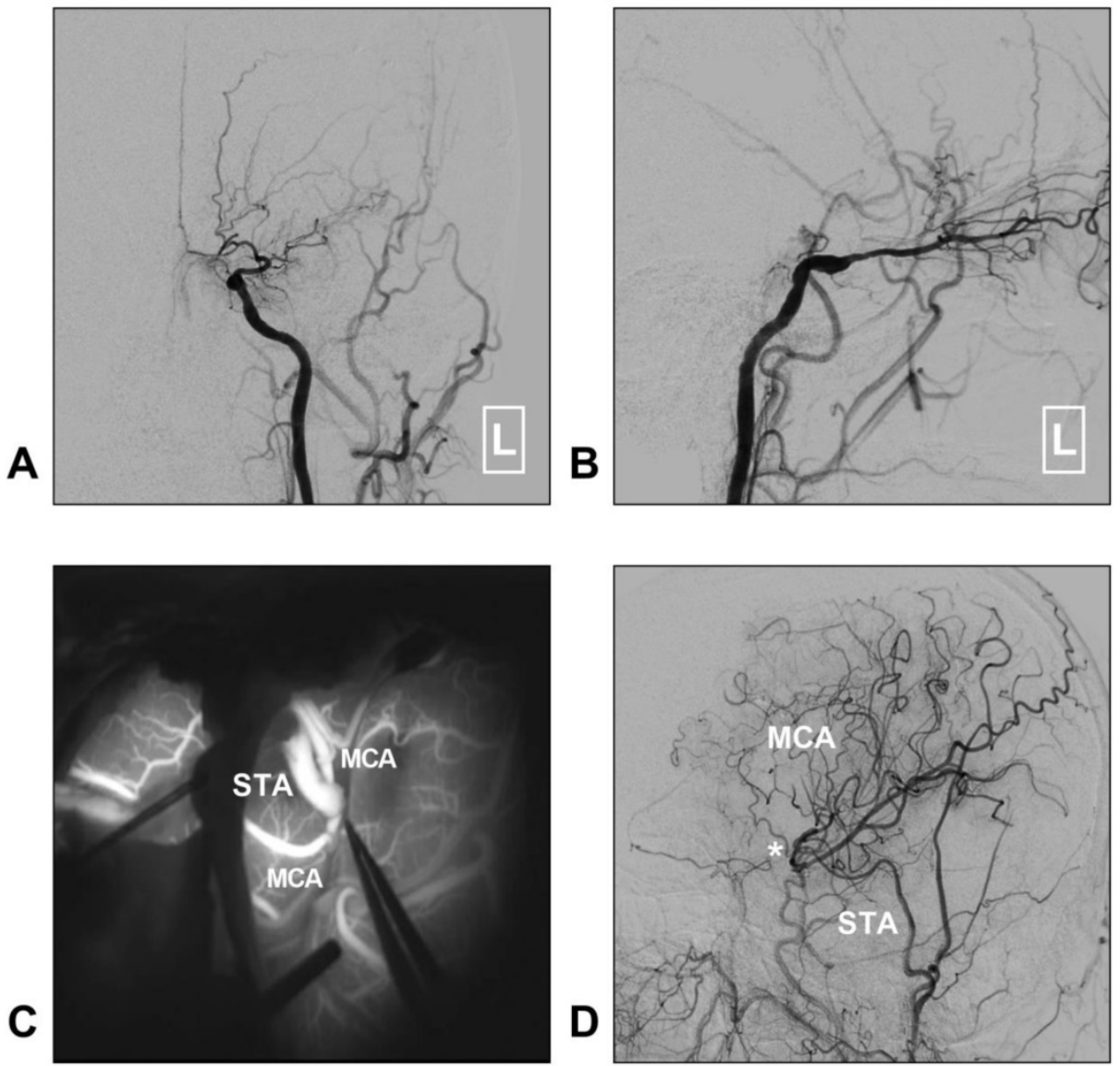

Figure 3. STA-MCA bypass for MMD. A-B: Left CCA angiogram shows steno-occlusive alteration of the ICA terminal; the ophthalmic artery is preserved. C: Intraoperative indocyanine green angiography shows that an STA-MCA bypass is established. D: Follow-up DSA shows that the distal MCA is reconstructed. The asterisk indicates the anastomosis point. Abbreviations: CCA: common carotid artery; DSA: digital subtraction angiography; MCA: middle cerebral artery; MMD: moyamoya disease; STA: superficial temporal artery. 


\section{(3). Bypass for intracranial complex aneurysms}

Complex aneurysms include large aneurysms, those with involvement of perforators, those from which branch arteries originate, or those that represent refractory lesions $[59,60]$. In treating these complex aneurysms, cerebral revascularization remains a major option that can serve as flow replacement bypass during aneurysmal trapping or insurance bypass during temporary parent artery occlusion [61].

In cerebral revascularizations, STA could serve as a donor vessel for low flow bypasses, which include STA-MCA, STA-anterior cerebral artery (ACA), and STA-superior cerebellar artery (SCA). In STA-ACA bypass, of note, an interposition graft may be needed for the long anatomical distance between STA and ACA. In case of high flow bypass between flow internal maxillary artery (IMA) and MCA, ACA, PCA, or ICA, STA can be used as an interposition vessel. [62-66]. In addition, the STA can also serve as an interposition graft in IC-IC bypass after aneurysm resection [67-71].

STA-MCA bypass is most suitable for complex MCA and ICA aneurysms when the recipient is the M3/M4 segment [61, 72]. To induce intra-aneurysmal thrombus and avoid distal ischemia, STA-MCA can be performed during proximal/distal clipping of the parent artery [61, 73]. Insurance STA-MCA bypass has been performed to support the MCA territory during its prolonged temporary occlusion or during installation of high-flow bypass [61].

STA-MCA bypass is the standard mode of cerebral revascularization in complex MCA and ICA aneurysms. However, STA-MCA bypass provides a low-flow system, and insufficient blood flow may result in negative events following therapeutic occlusion of the main trunk arteries that should be replaced by high-flow revascularization [74].
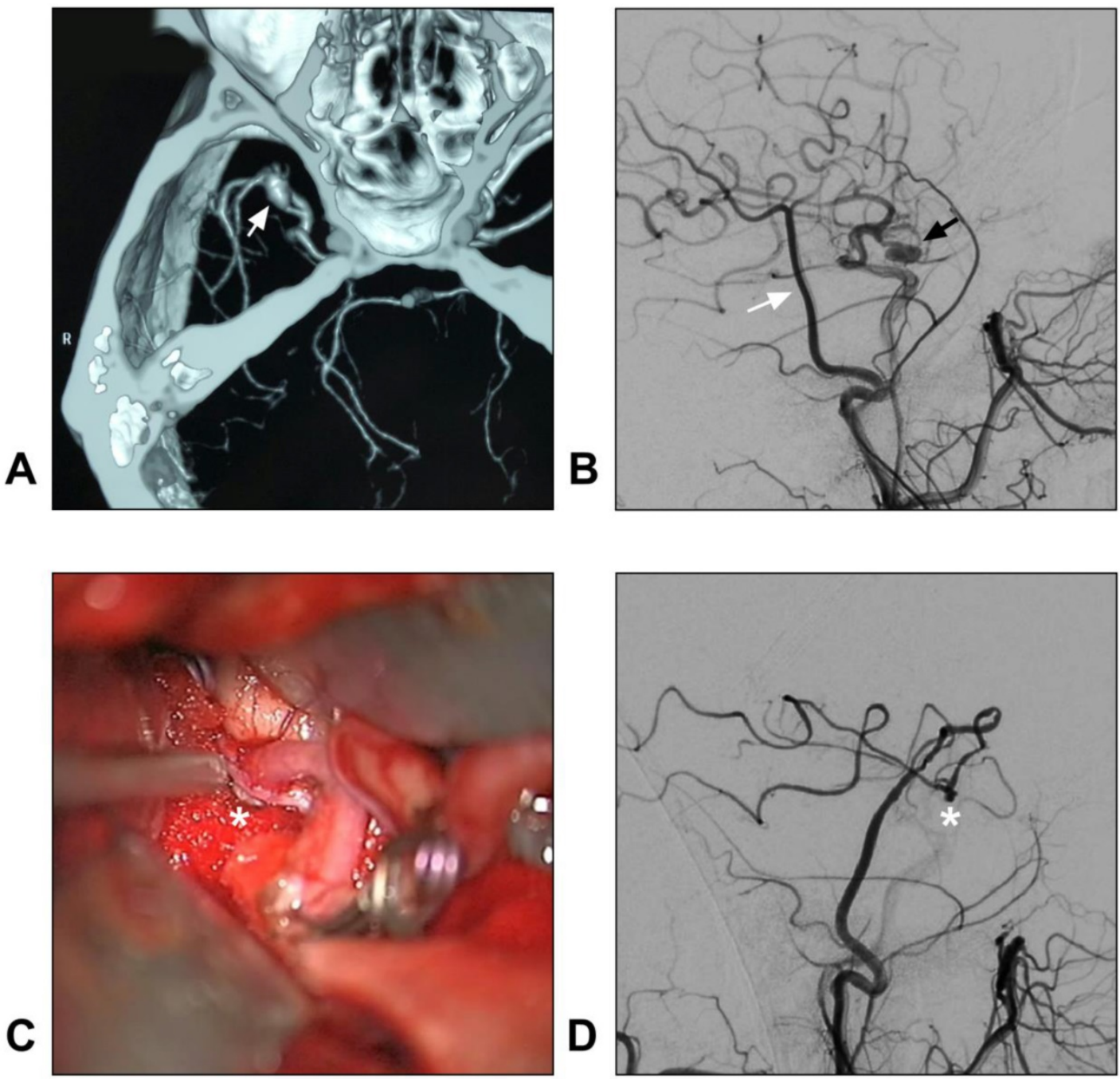

Figure 4. STA-MCA bypass for intracranial aneurysm. A: CTA reveals a dissecting aneurysm on the trunk of the MCA (arrow); B: DSA of the CCA shows the STA (white arrow) and aneurysm (black arrow); C: An end-to-side anastomosis between the STA and MCA trunk (asterisk) is performed; D: Postoperative angiogram of the ECA shows the STA-MCA bypass (asterisk) is patent. Abbreviations: CCA: common carotid artery; CTA: computed tomography angiography; DSA: digital subtraction angiography; ECA: external carotid artery; MCA: middle cerebral artery; STA: superficial temporal artery. 
The internal maxillary artery (IMA) is suitable to provide sufficient blood flow, and the STA trunk graft can be used for bypass of the IMA to proximal MCA in complex aneurysms [75-78]. Recently, IMA bypass was redefined as a new "workhorse" to replace conventional cervical artery bypass in the field of high-flow bypass [74, 79].

In addition, with a larger caliber, the STA trunk can provide more blood flow than the distal STA branches do. Hence, STA trunk-to-M2 of MCA or proximal PCA high-flow bypass with a short radial artery interposition graft should not be forgotten as it represents an excellent bypass to add to the armamentarium of choices when considering bypass options for complex aneurysms [80,81]. A typical case of an aneurysm treated with STA-MCA bypass is described in Figure 4.

\section{(4). Dural arteriovenous fistula}

DAVF is an arteriovenous shunt located in the dural wall. The meningeal branches of the ECA and

ICA are the main feeding arteries in DAVFs, with the middle meningeal artery (MMA) and OA the most commonly involved [82-84]. Occasionally, the STA can be involved in a DAVF. The location of fistula point in STA supplied DAVFs could be at the superior sagittal sinus, the transverse-sigmoid sinus, the anterior cranial fossa, or the tentorial region [6, 84-89]. When the STA serves as the main feeding artery, it can become swollen and thick [90,91].

Currently, in DAVF embolization, the STA is known to be poorly suitable because a pressure gradient of its transosseous branches may limit embolic agent penetration toward the shunt point [92, 93]. Recently, dual-lumen balloon has been proposed as a useful tool that may help to facilitate the penetration of liquid embolic agents from the STA [94]. However, DAVF embolization via the STA is not a completely safe path and it carries the risk of cast extrusion [95]. A DAVF case with STA as the feeding artery is described in Figure 5.
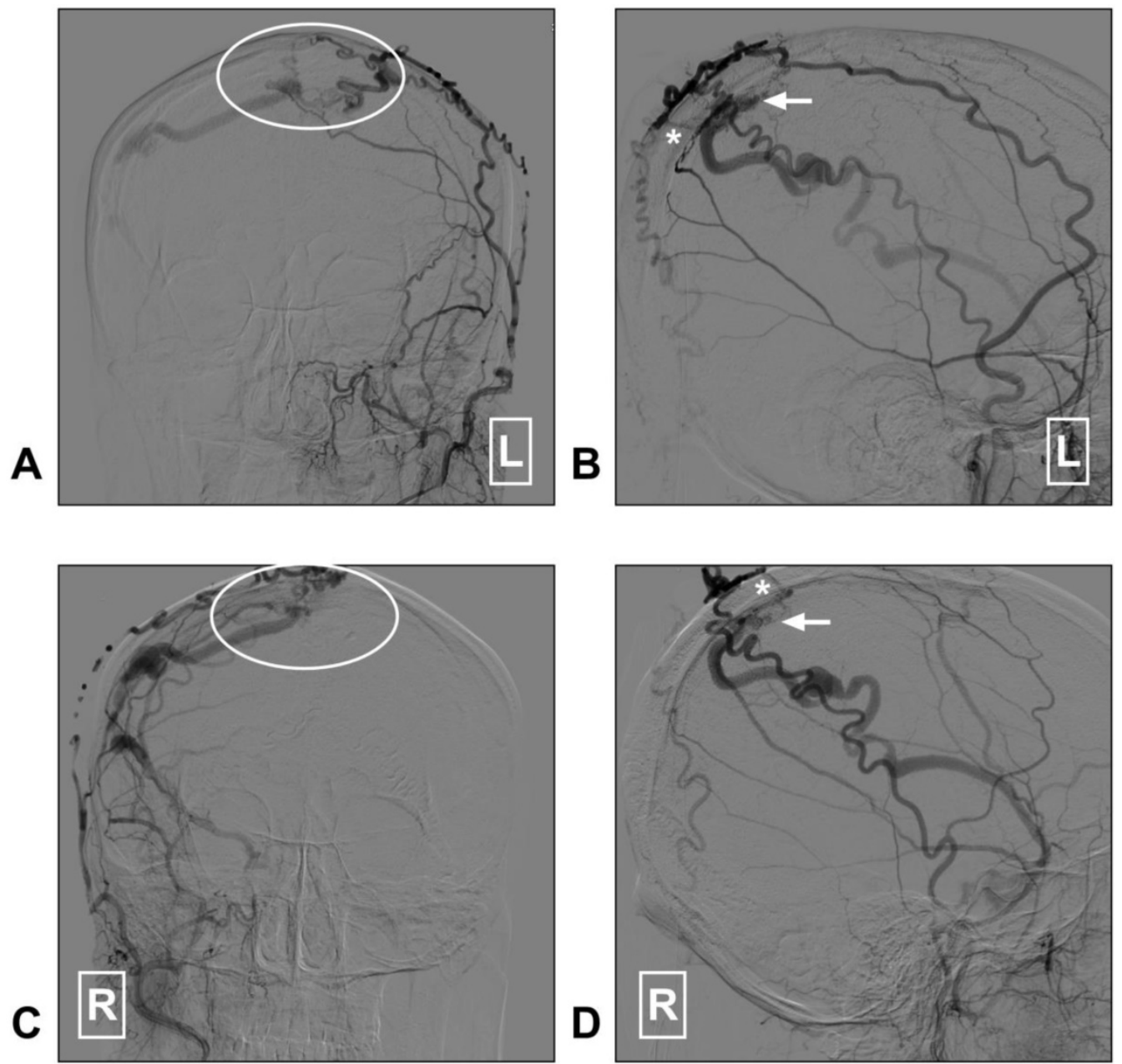

Figure 5. STA supplied superior sagittal sinus DAVF. A: Angiogram of the left ECA in AP view shows a superior sagittal sinus DAVF (white ellipse); B: Angiogram of the left ECA in lateral view shows the transosseous branches (asterisk) of the STA feed the DAVF. The arrow indicates the fistula point. C: Angiogram of the right ECA in AP view shows a superior sagittal sinus DAVF (white ellipse); D: Angiogram of the right ECA in lateral view indicates the fistula point (arrow). The transosseous branch (asterisk) of the right STA also feeds the DAVF. Abbreviation: AP: anterioposterior; DAVF: dural arteriovenous fistula; ECA: external carotid artery; L: right; R: right; STA: superficial temporal artery. 


\section{(5). Intraoperative angiography and EVT path}

In neurovascular diseases, intraoperative angiography is very useful for evaluating surgical clipping/excision and determining whether any residual lesion remains [96]. Seldinger technique, in which a catheter is advanced into the ICA or ECA through the femoral artery, is a standard method, but performing intraoperative angiography through the femoral artery is sometimes not convenient during a craniotomy [97].

The STA is a good path for intraoperative angiography [98]. STA puncture and retrograde advancement of the catheter down through the STA to the level of the carotid bifurcation could achieve intracranial angiography [7]. In order to preserve the STA main trunk after angiographic procedure, the division of the STA can be selected for the cannulation site [99].

Finally, the STA can be used as the path to perform EVTs [100, 101]. For instance, after the STA is exposed, incised and cannulated, a maxillary AVM can be embolized via the STA [102]. Alternatively, in selected cases, the STA may represent a valid alternative approach for performing an EVT in a short common carotid artery dissection [103].

\section{Conclusion}

This PRISMA-compliant systematic review of the clinical importance of STA in neurovascular diseases shows that the STA is one of the terminal branches of the external carotid artery and that it gives off many branches that supply the scalp and muscles. STA-MCA bypass is very useful for intracranial ischemic diseases. For intracranial complex aneurysms, STA bypass remains a major option that can serve as flow replacement bypass during aneurysmal trapping or insurance bypass during temporary parent artery occlusion. Occasionally, the STA can be involved in DAVFs via its transosseous branches. In addition, the STA can be used as a path for intraoperative angiography or performing an EVT procedure. Therefore, the STA is a very important artery in neurovascular diseases.

\section{Competing Interests}

The authors have declared that no competing interest exists.

\section{References}

1. Yonenaga K, Tohnai I, Mitsudo K, Mori Y, Saijo H, Iwai T, et al. Anatomical study of the external carotid artery and its branches for administration of superselective intra-arterial chemotherapy via the superficial temporal artery. Int J Clin Oncol. 2011; 16: 654-9.

2. Otsuka M, Kikkawa Y, Kamide T, Suzuki K, Shibata A, Ikeda T, et al. Factors related to improvement of cerebrovascular reserve after superficial temporal artery to middle cerebral artery anastomosis for patients with atherosclerotic steno-occlusive disease. Acta Neurochir (Wien). 2019; 161: 799-805.
3. Dhillon AZ, Levine T. Traumatic pseudoaneurysm of the superficial temporal artery. Br J Oral Maxillofac Surg. 2019; 57: 277-9.

4. Raheja A, Suri A, Sreenivasan SA, Singla R. Insurance and Flow-Alteration Superficial Temporal Artery to Middle Cerebral Artery (STA-MCA) Bypass in Management of Complex Anterior Intracranial Circulation Aneurysms in Postendovascular Era. World Neurosurg. 2019.

5. Janssen M, Vaninbroukx J, Fourneau I. Arteriovenous fistula after superficial temporal artery biopsy. Ann Vasc Surg. 2013; 27: 500 e1-5.

6. Hou K, Ji T, Guo Y, Xu B, Xu K, Yu J. Current Status of Endovascular Treatment for Dural Arteriovenous Fistulas in the Superior Sagittal Sinus Region: A Systematic Review of the Literature. World Neurosurg. 2019; 122: $133-43$.

7. Lee MC, Macdonald RL. Intraoperative cerebral angiography: superficial temporal artery method and results. Neurosurgery. 2003; 53: 1067-74; discussion 74-5

8. Cobb MI, Galvin L, Gonzalez LF. Superficial temporal artery: the "C" shape half-buttonhole configuration as it courses over the zygomatic arch. Surg Radiol Anat. 2016; 38: 493-5.

9. Hutton B, Salanti G, Caldwell DM, Chaimani A, Schmid CH, Cameron C, et al. The PRISMA extension statement for reporting of systematic reviews incorporating network meta-analyses of health care interventions: checklist and explanations. Ann Intern Med. 2015; 162: 777-84.

10. Lee JG, Yang HM, Hu KS, Lee YI, Lee HJ, Choi YJ, et al. Frontal branch of the superficial temporal artery: anatomical study and clinical implications regarding injectable treatments. Surg Radiol Anat. 2015; 37: 61-8.

11. Koziej M, Trybus M, Holda M, Wnuk J, Polak J, Brzegowy P, et al. The Superficial Temporal Artery: Anatomical Map for Facial Reconstruction and Aesthetic Procedures. Aesthet Surg J. 2018.

12. Manoli T, Medesan R, Held M, Schaller HE, Ernemann U, Korn A, et al. Bilateral comparison of the vascular pattern of the superficial temporal artery based on digital subtraction angiography. Surg Radiol Anat. 2016; 38: 179-86.

13. Marano SR, Fischer DW, Gaines C, Sonntag VK. Anatomical study of the superficial temporal artery. Neurosurgery. 1985; 16: 786-90.

14. Elazab EE, Abdel-Hameed FA. The arterial supply of the temporalis muscle. Surg Radiol Anat. 2006; 28: 241-7.

15. Zhou EJ, Sweeney AR, Chen SR, Yen MT. Intraorbital Arteriovenous Fistula From the Superficial Temporal Artery. Ophthalmic Plast Reconstr Surg. 2019.

16. Nakajima $\mathrm{H}$, Imanishi $\mathrm{N}$, Minabe $\mathrm{T}$. The arterial anatomy of the temporal region and the vascular basis of various temporal flaps. Br J Plast Surg. 1995; 48: 439-50.

17. Kim BS, Jung YJ, Chang CH, Choi BY. The anatomy of the superficial temporal artery in adult koreans using 3-dimensional computed tomographic angiogram: clinical research. J Cerebrovasc Endovasc Neurosurg. 2013; 15: 145-51.

18. Pinar YA, Govsa F. Anatomy of the superficial temporal artery and its branches: its importance for surgery. Surg Radiol Anat. 2006; 28: 248-53.

19. Medved F, Manoli T, Medesan R, Janghorban Esfahani B, Stahl S, Schaller HE, et al. In vivo analysis of the vascular pattern of the superficial temporal artery based on digital subtraction angiography. Microsurgery. 2015; 35: 380-6.

20. Farsad K, Hayek RA, Mamourian AC, Friedman JA. Computerized tomographic angiography for preoperative assessment of the superficial temporal artery for external carotid artery to internal carotid artery bypass: Case illustration. Cases J. 2008; 1: 119

21. Yu J, Shi L, Guo Y, Xu B, Xu K. Progress on Complications of Direct Bypass for Moyamoya Disease. Int J Med Sci. 2016; 13: 578-87.

22. Kraemer M, Sassen J, Karakaya R, Schwitalla JC, Graf J, Albrecht P, et al. Moyamoya angiopathy: early postoperative course within 3 months after STA-MCA-bypass surgery in Europe-a retrospective analysis of 64 procedures. J Neurol. 2018; 265: 2370-8.

23. Li Q, Qu L, Yuan Y, Xu B, Guo Y, Xu K, et al. Analysis of the clinical characteristics of hemorrhagic moyamoya disease in the Jilin province of northeastern China: A single-center study of 212 cases. Biomed Rep. 2018; 8: 191-7.

24. Jang DK, Lee KS, Rha HK, Huh PW, Yang JH, Park IS, et al. Bypass surgery versus medical treatment for symptomatic moyamoya disease in adults. J Neurosurg. 2017; 127: 492-502.

25. Herve D, Kossorotoff M, Bresson D, Blauwblomme T, Carneiro M, Touze E, et al. French clinical practice guidelines for Moyamoya angiopathy. Rev Neurol (Paris). 2018; 174: 292-303.

26. Piao J, Wu W, Yang Z, Yu J. Research Progress of Moyamoya Disease in Children. Int J Med Sci. 2015; 12: 566-75.

27. Bot GM, Burkhardt JK, Gupta N, Lawton MT. Superficial temporal artery-to-middle cerebral artery bypass in combination with indirect revascularization in moyamoya patients $</=3$ years of age. J Neurosurg Pediatr. 2018; 23: 198-203.

28. Park SE, Kim JS, Park EK, Shim KW, Kim DS. Direct versus indirect revascularization in the treatment of moyamoya disease. J Neurosurg. 2018; 129: 480-9.

29. Abla AA, Gandhoke G, Clark JC, Oppenlander ME, Velat GJ, Zabramski JM, et al. Surgical outcomes for moyamoya angiopathy at barrow neurological institute with comparison of adult indirect encephaloduroarteriosynangiosis bypass, adult direct superficial temporal artery-to-middle cerebral artery bypass, and pediatric bypass: 154 revascularization surgeries in 140 affected hemispheres. Neurosurgery. 2013; 73: 430-9. 
30. Chen H, Hou K, Wang X, Xu K, Yu J. Spontaneous recession of a posterior cerebral artery aneurysm concurrent with carotid rete mirabile and moyamoya-pattern collateral vessels: a case report. BMC Neurol. 2019; 19: 51.

31. Yan Y, Li Y, Huang L, Zhang S. A Comprehensive Meta-Analysis for Bypass Surgery in Adult Moyamoya. World Neurosurg. 2019.

32. Zhang $\mathrm{L}$, Xu K, Zhang $\mathrm{Y}$, Wang $\mathrm{X}, \mathrm{Yu}$ J. Treatment strategies for aneurysms associated with moyamoya disease. Int J Med Sci. 2015; 12: 234-42.

33. Kazumata K, Kamiyama H, Saito H, Maruichi K, Ito M, Uchino H, et al. Direct Anastomosis Using Occipital Artery for Additional Revascularization in Moyamoya Disease After Combined Superficial Temporal Artery-Middle Cerebral Artery and Indirect Bypass. Oper Neurosurg (Hagerstown). 2017; 13: 213-23.

34. Rutledge WC, Choudhri O, Walcott BP, Benet A, Fox CK, Gupta N, et al. Indirect and direct revascularization of ACTA2 cerebral arteriopathy: feasibility of the superficial temporal artery to anterior cerebral artery bypass with posterior auricular artery interposition graft: case report. J Neurosurg Pediatr. 2016; 18: 339-43.

35. Cherian J, Srinivasan V, Kan P, Duckworth EAM. Double-Barrel Superficial Temporal Artery-Middle Cerebral Artery Bypass: Can It Be Considered "High-Flow?". Oper Neurosurg (Hagerstown). 2018; 14: 288-94.

36. Arnone GD, Hage ZA, Charbel FT. Single Vessel Double Anastomosis for Flow Augmentation - A Novel Technique for Direct Extracranial to Intracranial Bypass Surgery. Oper Neurosurg (Hagerstown). 2019.

37. Yoshimura S, Egashira Y, Enomoto Y, Yamada K, Yano H, Iwama T. Superficial temporal artery to middle cerebral artery double bypass via a small craniotomy: technical note. Neurol Med Chir (Tokyo). 2010; 50: 956-9.

38. Ishiguro T, Okada $\mathrm{Y}$, Ishikawa $\mathrm{T}$, Yamaguchi $\mathrm{K}$, Kawashima A, Kawamata T. Efficacy of superficial temporal artery-middle cerebral artery double bypass in patients with hemorrhagic moyamoya disease: surgical effects for operated hemispheric sides. Neurosurg Rev. 2018.

39. Ha M, Choi CH, Lee JI, Cha SH, Lee SW, Ko JK. The Efficacy of Single Barrel Superficial Temporal Artery-middle Cerebral Artery Bypass in Treatment of Adult Patients with Ischemic-type Moyamoya Disease. J Cerebrovasc Endovasc Neurosurg. 2016; 18: 239-46.

40. Ishii D, Okazaki T, Matsushige T, Shinagawa K, Sakamoto S, Oshita J, et al Chronic Dilatation of Superficial Temporal Artery and Middle Meningeal Artery Associated with Development of Collateral Circulation After Bypass Surgery for Moyamoya Angiopathy. World Neurosurg. 2018; 119: e864-e73.

41. White TG, Abou-Al-Shaar H, Park J, Katz J, Langer DJ, Dehdashti AR. Cerebral revascularization after the Carotid Occlusion Surgery Study: what candidates remain, and can we do better? Neurosurg Focus. 2019; 46: E3.

42. Group EIBS. Failure of extracranial-intracranial arterial bypass to reduce the risk of ischemic stroke. Results of an international randomized trial. N Engl J Med. 1985; 313: 1191-200.

43. Powers WJ, Clarke WR, Grubb RL, Jr., Videen TO, Adams HP, Jr., Derdeyn $\mathrm{CP}$, et al. Extracranial-intracranial bypass surgery for stroke prevention in hemodynamic cerebral ischemia: the Carotid Occlusion Surgery Study randomized trial. JAMA. 2011; 306: 1983-92.

44. Gunawardena M, Rogers JM, Stoodley MA, Morgan MK. Revascularization surgery for symptomatic non-moyamoya intracranial arterial stenosis or occlusion. J Neurosurg. 2019: 1-6.

45. Neff KW, Horn P, Dinter D, Vajkoczy P, Schmiedek P, Duber C Extracranial-intracranial arterial bypass surgery improves total brain blood supply in selected symptomatic patients with unilateral internal carotid artery occlusion and insufficient collateralization. Neuroradiology. 2004; 46: 730-7.

46. Hanggi D, Reinert M, Steiger HJ. C-Port Flex-A-assisted automated anastomosis for high-flow extracranial-intracranial bypass surgery in patients with symptomatic carotid artery occlusion: a feasibility study. Clinical article. J Neurosurg. 2009; 111: 181-7.

47. Esposito G, Amin-Hanjani S, Regli L. Role of and Indications for Bypass Surgery After Carotid Occlusion Surgery Study (COSS)? Stroke. 2016; 47: 282-90

48. Low SW, Teo K, Lwin S, Yeo LL, Paliwal PR, Ahmad A, et al. Improvement in cerebral hemodynamic parameters and outcomes after superficial temporal artery-middle cerebral artery bypass in patients with severe stenoocclusive disease of the intracranial internal carotid or middle cerebral arteries. J Neurosurg. 2015; 123: 662-9.

49. Matano F, Murai Y, Tateyama K, Tamaki T, Mizunari T, Matsukawa H, et al. Long-term patency of superficial temporal artery to middle cerebral artery bypass for cerebral atherosclerotic disease: factors determining the bypass patent. Neurosurg Rev. 2016; 39: 655-61.

50. Inoue A, Kohno $K$, Iwata $S$, Ohue S, Ozaki S, Ninomiya S, et al. Efficacy of Early Superficial Temporal Artery-Middle Cerebral Artery Double Anastomoses for Atherosclerotic Occlusion in Patients with Progressing Stroke. J Stroke Cerebrovasc Dis. 2017; 26: 741-8.

51. Chen C, Wei L, Li M, Ling C, Luo L, Guo Y, et al. Superficial temporal artery trunk to middle cerebral artery bypass with short radial artery interposition graft for symptomatic internal carotid artery occlusion. World Neurosurg. 2019.

52. Rice CJ, Cho SM, Taqui A, Moore NZ, Witek AM, Bain MD, et al. Early versus Delayed Extracranial-Intracranial Bypass Surgery in Symptomatic Atherosclerotic Occlusion. Neurosurgery. 2018.

53. Yoshimoto Y, Kwak S. Superficial temporal artery--middle cerebral artery anastomosis for acute cerebral ischemia: the effect of small augmentation of blood flow. Acta Neurochir (Wien). 1995; 137: 128-37, discussion 37.
54. Lee SB, Huh PW, Kim DS, Yoo DS, Lee TG, Cho KS. Early superficial temporal artery to middle cerebral artery bypass in acute ischemic stroke. Clin Neurol Neurosurg. 2013; 115: 1238-44.

55. Hwang G, Oh CW, Bang JS, Jung CK, Kwon OK, Kim JE, et al. Superficial temporal artery to middle cerebral artery bypass in acute ischemic stroke and stroke in progress. Neurosurgery. 2011; 68: 723-9; discussion 9-30.

56. Park HS, Kim SH, Nah HW, Choi JH, Kim DH, Kang MJ, et al. Patient Selection and Clinical Efficacy of Urgent Superficial Temporal Artery-Middle Cerebral Artery Bypass in Acute Ischemic Stroke Using Advanced Magnetic Resonance Imaging Techniques. Oper Neurosurg (Hagerstown). 2017; 13: $552-9$.

57. Burkhardt JK, Winklhofer S, Fierstra J, Wegener S, Esposito G, Luft A, et al. Emergency Extracranial-Intracranial Bypass to Revascularize Salvageable Brain Tissue in Acute Ischemic Stroke Patients. World Neurosurg. 2018; 109: e476-e85.

58. Horiuchi T, Nitta J, Ishizaka S, Kanaya K, Yanagawa T, Hongo K. Emergency EC-IC bypass for symptomatic atherosclerotic ischemic stroke. Neurosurg Rev. 2013; 36: 559-64; discussion 64-5.

59. Brassel F, Grieb D, Meila D, Schlunz-Hendann M, Greling B, Melber K. Endovascular treatment of complex intracranial aneurysms using Acandis Acclino stents. J Neurointerv Surg. 2017; 9: 854-9.

60. Seo BR, Kim TS, Joo SP, Lee JM, Jang JW, Lee JK, et al. Surgical strategies using cerebral revascularization in complex middle cerebral artery aneurysms. Clin Neurol Neurosurg. 2009; 111: 670-5.

61. Raheja A, Suri A, Sreenivasan SA, Singla R. Insurance and Flow-Alteration Superficial Temporal Artery to Middle Cerebral Artery (STA-MCA) Bypass in Management of Complex Anterior Intracranial Circulation Aneurysms in Postendovascular Era. World Neurosurgery. 2019.

62. Rubio RR, Gandhi S, Benet A, Tabani H, Burkhardt J-K, Kola O, et al. Internal Maxillary Artery to Anterior Circulation Bypass with Local Interposition Grafts Using a Minimally Invasive Approach: Surgical Anatomy and Technical Feasibility. World Neurosurgery. 2018; 120: e503-e10.

63. Wada K, Otani N, Toyooka T, Takeuchi S, Tomiyama A, Mori K. Superficial Temporal Artery to Anterior Cerebral Artery Hemi-bonnet Bypass Using Radial Artery Graft for Prevention of Complications after Surgical Treatment of Partially Thrombosed Large/Giant Anterior Cerebral Artery Aneurysm. J Stroke Cerebrovasc Dis. 2018; 27: 3505-10.

64. Tayebi Meybodi A, Lawton MT, Rodriguez Rubio R, Yousef S, Guo X, Feng X, et al. Internal Maxillary Artery to Upper Posterior Circulation Bypass Using a Superficial Temporal Artery Graft: Surgical Anatomy and Feasibility Assessment. World Neurosurg. 2017; 107: 314-21.

65. Takeuchi S, Tanikawa R, Tsuboi T, Noda K, Oda J, Miyata S, et al. Superficial temporal artery to proximal posterior cerebral artery bypass through the anterior temporal approach. Surg Neurol Int. 2015; 6: 95.

66. Ausman JI, Diaz FG, de los Reyes RA, Pak H, Patel S, Mehta B, et al Posterior circulation revascularization. Superficial temporal artery to superior cerebellar artery anastomosis. J Neurosurg. 1982; 56: 766-76.

67. Wang L, Cai L, Qian $\mathrm{H}$, Song J, Tanikawa $\mathrm{R}$, Lawton $\mathrm{M}$, et al. Intracranial-intracranial bypass with a graft vessel: a comprehensive review of technical characteristics and surgical experience. World Neurosurg. 2019.

68. Endo H, Sugiyama SI, Endo T, Fujimura M, Shimizu H, Tominaga $T$. Revascularization of the anterior cerebral artery by Y-shaped superficial temporal artery interposition graft for the treatment of a de novo aneurysm arising at the site of A3-A3 bypass: technical case report. J Neurosurg. 2018; 129: $1120-4$

69. Abe T, Endo H, Shimizu H, Fujimura M, Endo T, Sakata H, et al. A case of ruptured infectious anterior cerebral artery aneurysm treated by interposition graft bypass using the superficial temporal artery. Surg Neurol Int. 2016; 7: 5.

70. Hamada J, Todaka $T$, Yano S, Kai $Y$, Morioka M, Ushio $Y$. Vertebral artery-posterior inferior cerebellar artery bypass with a superficial temporal artery graft to treat aneurysms involving the posterior inferior cerebellar artery. J Neurosurg. 2002; 96: 867-71.

71. Buyukmumcu M, Guney O, Ustun ME, Uysal, II, Seker M. Proximal superficial temporal artery to proximal middle cerebral artery bypass using a radial artery graft: an anatomic approach. Neurosurg Rev. 2004; 27: 185-8.

72. Kalani MY, Hu YC, Spetzler RF. A double-barrel superficial temporal artery-to-superior cerebellar artery (STA-SCA) and STA-to-posterior cerebral artery (STA-PCA) bypass for revascularization of the basilar apex. J Clin Neurosci. 2013; 20: 887-9.

73. Soldozy S, Costello JS, Norat P, Sokolowski JD, Soldozy K, Park MS, et al. Extracranial-intracranial bypass approach to cerebral revascularization: a historical perspective. Neurosurg Focus. 2019; 46: E2.

74. Wang L, Lu S, Cai L, Qian H, Tanikawa R, Shi Xe. Internal maxillary artery bypass for the treatment of complex middle cerebral artery aneurysms. Neurosurgical Focus. 2019; 46: E10.

75. Abe M, Uetsuki T. [Clinico-pathological study of diseases of the central nervous system. VII. Autopsied case of a large aneurysm in the left anterior inferior cerebellar artery]. No To Shinkei. 1968; 20: 933-9.

76. Arbag H, Cicekcibasi AE, Uysal, II, Ustun ME, Buyukmumcu M. Superficial temporal artery graft for bypass of the maxillary to proximal middle cerebral artery using a transantral approach: an anatomical and technical study. Acta Otolaryngol. 2005; 125: 999-1003.

77. Meybodi AT, Lawton MT, El-Sayed I, Davies J, Tabani H, Feng X, et al. The Infrazygomatic Segment of the Superficial Temporal Artery: Anatomy and 
Technique for Harvesting a Better Interposition Graft. Oper Neurosurg (Hagerstown). 2017; 13: 517-21.

78. Alaraj A, Ashley WW, Jr., Charbel FT, Amin-Hanjani S. The superficial temporal artery trunk as a donor vessel in cerebral revascularization: benefits and pitfalls. Neurosurg Focus. 2008; 24: E7.

79. Feng X, Meybodi AT, Rincon-Torroella J, El-Sayed IH, Lawton MT, Benet A. Surgical Technique for High-Flow Internal Maxillary Artery to Middle Cerebral Artery Bypass Using a Superficial Temporal Artery Interposition Graft. Oper Neurosurg (Hagerstown). 2017; 13: 246-57.

80. Abla AA, Lawton MT. The superficial temporal artery trunk-to-M2 middle cerebral artery bypass with short radial artery interposition graft: the forgotten bypass. World Neurosurg. 2015; 83: 145-6.

81. Ulku CH, Cicekcibasi AE, Cengiz SL, Ustun ME, Buyukmumcu M. Proximal STA to proximal PCA bypass using a radial artery graft by posterior oblique transzygomatic subtemporal approach. Neurosurg Rev. 2009; 32: 95-9; discussion 9.

82. Li G, Zhang Y, Zhao J, Zhu X, Yu J, Hou K. Isolated subdural hematoma secondary to Dural arteriovenous fistula: a case report and literature review. BMC Neurol. 2019; 19: 43.

83. Xu K, Hou K, Xu B, Guo Y, Yu J. Dural Arteriovenous Fistula Between the Inferolateral Trunk and Cavernous Sinus Draining to Ophthalmic Vein. World Neurosurg. 2018; 117: 231-7.

84. Xu K, Yang X, Li C, Yu J. Current status of endovascular treatment for dural arteriovenous fistula of the transverse-sigmoid sinus: A literature review. Int J Med Sci. 2018; 15: 1600-10.

85. Xu K, Ji T, Li C, Yu J. Current status of endovascular treatment for dural arteriovenous fistulae in the anterior cranial fossa: A systematic literature review. Int J Med Sci. 2019; 16: 203-11.

86. Tong D, Chen X, Lv X, Li K, Xu K, Yu J. Current status of endovascular treatment for dural arteriovenous fistulae in the tentorial middle region: a literature review. Acta Neurol Belg. 2019; 119: 5-14.

87. $\mathrm{Li} \mathrm{C}, \mathrm{Yu}$ J, Li K, Hou K, Yu J. Dural arteriovenous fistula of the lateral foramen magnum region: A review. Interv Neuroradiol. 2018; 24: 425-34.

88. Chen $\mathrm{Z}$, Miao $\mathrm{H}$, Feng $\mathrm{H}$, Zhu G. Prominent forehead scalp arteries a diagnostic clue to unruptured anterior cranial fossa dural arteriovenous fistula. Arch Neurol. 2011; 68: 824-5.

89. Shen SC, Chen WH, Chen SY, Sun MH, Shen CC, Tsuei YS. Temporary clamping of bilateral external carotid arteries for surgical excision of a complex dural arteriovenous fistula. Surg Neurol Int. 2014; 5: 10.

90. Haisa T, Shojima M. Swollen superficial temporal artery in dural arteriovenous fistula. Neurol Clin Pract. 2016; 6: e33-e4.

91. Guo Y, Yu J, Zhao Y, Yu J. Progress in research on intracranial multiple dural arteriovenous fistulas. Biomed Rep. 2018; 8: 17-25.

92. Yu J, Guo Y, Xu B, Xu K. Clinical importance of the middle meningeal artery: A review of the literature. Int J Med Sci. 2016; 13: 790-9.

93. Cognard C, Januel AC, Silva NA, Jr., Tall P. Endovascular treatment of intracranial dural arteriovenous fistulas with cortical venous drainage: new management using Onyx. AJNR Am J Neuroradiol. 2008; 29: 235-41.

94. Clarencon F, Di Maria F, Gabrieli J, Carpentier A, Pistochi S, Bartolini B, et al. Double-lumen balloon for $\operatorname{Onyx}(\mathrm{R})$ embolization via extracranial arteries in transverse sigmoid dural arteriovenous fistulas: initial experience. Acta Neurochir (Wien). 2016; 158: 1917-23.

95. Watanabe J, Maruya J, Nishimaki K, Ito Y. Onyx removal after embolization of a superior sagittal sinus dural arteriovenous fistula involving scalp artery. Surg Neurol Int. 2016; 7: S410-4

96. Shi L, Li W, Xu K, Guo YB, Yu JL. Current status of combined surgical and endovascular methods for intracranial neurovascular diseases in a hybrid operating room. Int J Clin Exp Med. 2016; 9: 20741-53.

97. Yu JL, Guo YB, Xu BF, Chen X, Xu K. Onyx embolization and surgical removal as a treatment for hemorrhagic AVM in a hybrid operating room. Int J Clin Exp Med. 2016; 9: 22494-501.

98. Ichikawa $\mathrm{T}$, Suzuki $\mathrm{K}$, Watanabe $\mathrm{Y}$. Intra-arterial fluorescence angiography with injection of fluorescein sodium from the superficial temporal artery during aneurysm surgery: technical notes. Neurol Med Chir (Tokyo). 2014; 54: 490-6.

99. Sheikh BY. Minimal invasive method for intraoperative angiography using the superficial temporal artery with preservation of its trunk. Surg Neurol. 2008; 70: 640-3; discussion 3-4.

100. Funakoshi $\mathrm{Y}$, Hatano T, Saka M, Ando M, Chihara H, Takita W, et al. Dural and Pial Arteriovenous Fistulas Connected to the Same Drainer in the Middle Cranial Fossa: A Case Report. World Neurosurg. 2018; 118: 47-52.

101. Hada Y, Hattori T, Seta $H$, Yanohara $K$, Kato A, Takahashi $Y$, et al. [Embolization of the internal maxillary artery for severe epistaxis--including an experience of the approach from the superficial temporal artery]. Nihon Igaku Hoshasen Gakkai Zasshi. 1993; 53: 229-31.

102. Wang C, Yan Q, Xie X, Li J, Zhou D. Embolization of a bleeding maxillary arteriovenous malformation via the superficial temporal artery after external carotid artery ligation. Korean J Radiol. 2008; 9: 182-5.

103. Stella N, Palombo G, Filippi F, Fantozzi C, Taurino M. Endovascular treatment of common carotid artery dissection via the superficial temporal artery. J Endovasc Ther. 2010; 17: 569-73. 